\title{
Aetiopathogenesis of atopic dermatitis
}

H F Jordaan, ${ }^{1} \mathrm{MB}$ ChB, MMed (Derm); G Todd, ${ }^{2} \mathrm{MB}$ ChB, FCDerm (SA), PhD; W Sinclair, ${ }^{3} \mathrm{MB}$ ChB, MMed (Derm); R J Green, ${ }^{4} \mathrm{MB}$ BCh, DCH, FCP(SA), DTM\&H, MMed, FCCP, PhD, Dip Allergology (SA), DSc

${ }^{1}$ Division of Dermatology, Department of Medicine, Faculty of Medicine and Health Sciences, Stellenbosch University, Cape Town, South Africa ${ }^{2}$ Department of Medicine, Faculty of Health Sciences, University of Cape Town, South Africa

${ }^{3}$ Department of Dermatology, Faculty of Health Sciences, University of the Free State, Bloemfontein, South Africa

${ }^{4}$ Department of Paediatrics and Child Health, Faculty of Health Sciences, University of Pretoria, South Africa

Corresponding author: W Sinclair (sinclairw@ufs.ac.za)

The aetiopathogenesis of atopic dermatitis (AD) is complex and during recent years much has been learnt regarding the genetic predisposition to the development of this condition and how its interaction with the environment influences clinical manifestations. AD is not a simple allergic condition. An inherited stratum corneum barrier defect, transepidermal water loss, early antigen exposure through the skin and over-hygienic care of the young child seem to be the major drivers in the manifestation of the disease. Many other, more specific, environmental factors may influence the clinical picture in individual patients; some of these have an allergic basis, while others do not.

In this article, the terminology used in this issue of CME is explained, the evidence for the different aetiopathological factors is presented and the factors that worsen or improve $\mathrm{AD}$ are listed.

S Afr Med J 2014;104(10):706-709. DOI:10.7196/SAMJ.8840

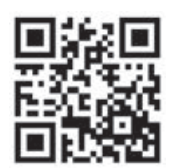

Definitions and terminology

The word eczema derives from the Greek word for 'boiling over'. Eczema periodically flares up (or boils over). The term dermatitis refers to inflammation of the skin, analogous to appendicitis (inflammation of the appendix), hepatitis (inflammation of the liver), etc. Currently, the terms dermatitis and eczema are generally regarded as synonyms. Internationally, however, there is no agreement on the use of these terms. The word eczema tends to be a layman's term, while dermatitis is more often used in a scientific context.

Eczema/dermatitis is not a diagnosis. The most common forms of eczema/dermatitis are atopic, seborrhoeic, primary irritant, allergic contact, photoallergic, phototoxic, nummular, asteatotic, stasis and dyshydrotic.

Atopy may be defined as a clinical hypersensitivity state subject to hereditary influences, including hay fever, asthma and eczema, developing against a complex genetic background - the so-called atopic diathesis. In the 1980s, Hanifin and Rajka proposed a list of criteria, leading to agreement regarding the clinical concept of atopic dermatitis (AD). In 1994, a UK Working Party refined these criteria in a concise and validated set of survey-based diagnostic criteria useful for the purposes of epidemiological studies, as set out below.

Atopic in the term atopic eczema is simply an indicator of the frequent association of this condition with atopy and the need to separate this clinical phenotype from other forms of eczema. The terms atopic eczema and $\mathrm{AD}$ are synonymous.

According to the position paper of the Nomenclature Review Committee of the World Allergy Association, ${ }^{[1]}$ the term atopic eczema/dermatitis syndrome (AEDS) should be used as the umbrella term covering the different subtypes of $\mathrm{AD}$. The new nomenclature (AEDS) underlines that $\mathrm{AD}$ is not one single disease entity, but rather an aggregation of several diseases that have certain clinical characteristics in common.

Intrinsic $\mathrm{AD}$ (non-allergic AEDS (NAAEDS) or atopiform dermatitis) fulfils the most commonly used diagnostic criteria for $\mathrm{AD}$. Patients with intrinsic $\mathrm{AD}$ have no associated respiratory diseases, such as bronchial asthma or allergic rhinitis, present with normal total serum IgE levels, have no specific IgE, and manifest negative skin-prick tests to aeroallergens or foods. In one study, intrinsic $\mathrm{AD}$ was more common in females and disease onset was later. This group comprised at least $20 \%$ (up to $60 \%$ ) of cases. ${ }^{[2]}$

Extrinsic AD (allergic AEDS (AAEDS)) is commonly associated with respiratory allergies such as rhinitis and asthma, high levels of serum IgE, specific IgE, and positive skin-prick tests to aeroallergens or foods. Immunological differences between NAAEDS and AAEDS can be found in the cell and cytokine patterns in peripheral blood and 
affected skin, and also by phenotyping characterisation of epidermal dendritic cells. This group comprises $40-80 \%$ of patients. ${ }^{[2]}$

The classification into AAEDS and NAAEDS at each stage of life, i.e. infancy, childhood, adolescence and adulthood, is essential for the allergological management of patients regarding allergen avoidance, secondary allergy prevention, and immunotherapy. The risk of an 'atopy march' is significantly lower in children with NAAEDS than in those with AAEDS. ${ }^{[3]}$ This subdivision is controversial. Cases may transform from one type to another and this division may not be applicable to adults. Until the exact genetic and causative agents are known, one should consider the clinical disease as one condition.

Acute eczema/dermatitis is characterised by oedema, erythema, vesiculation, exudation and crusting. Chronic eczema/dermatitis is characterised by lichenification, which refers to thickening of the skin with exaggeration of normal markings. Flat-topped, shiny, quadrilateral coalescing papules are enclosed. Subacute eczema/ dermatitis shows features that overlap with those of acute and chronic eczema/dermatitis, i.e. commonly slightly elevated, and red, brownish or purplish in colour, with variable scaling. Generally, the subacute presentation of eczema/dermatitis is more common.

The morphology, distribution and evolution of eczema/dermatitis in atopic eczema/dermatitis are highly characteristic and age dependent:

- Infant phase (birth - 2 years): red scaly lesions typically develop on the cheeks, usually sparing the peri-oral and perinasal areas. The chin is typically involved and cheilitis is common. A small but significant number of infants develop a generalised eruption, and involvement of the scalp is not uncommon. The nappy area is often spared, but sometimes the cubital/popliteal fossae or other parts of the limbs are involved.

- Childhood phase ( 2 - 12 years): eczema/dermatitis involves the flexural areas (i.e. the cubital and popliteal fossae) and the neck, wrist and ankles.

- Adolescent and adult phases (12 years - adulthood): involvement is similar to the childhood phase. Additionally, hand, peri-ocular and anogenital eczema/dermatitis are common. Sometimes lesions occur on extensor surfaces, and follicular accentuation may be prominent.

Morphologically, lesions may be classified as acute, subacute or chronic. Atopic eczema is a difficult disease to define, as the clinical features are highly variable with regard to morphology, body site and time. Diagnosis is therefore essentially clinical. ${ }^{[4]}$

\section{Aetiopathogenesis}

The aetiopathogenesis of $\mathrm{AD}$ is probably multifactorial. Current thinking favours a skin barrier defect as the most significant predisposing factor, where mutations in the filaggrin gene feature strongly. ${ }^{[5,6]}$ Most studies on the causes of $\mathrm{AD}$ have been performed in children. There is little to suggest that adult AD should have a different aetiopathogenesis, except for some clinical features that differ, such as the predominant involvement of the hands and the head and neck. ${ }^{[7]}$

\section{Genetics}

Population-based family studies in Europe suggest that in atopic families up to $50 \%$ of offspring will have $\mathrm{AD} \cdot{ }^{[8]}$ Twin studies showing a concordance rate of 0.75 for monozygotic twins and 0.20 for dizygotic twins support a genetic basis for $\mathrm{AD} \cdot{ }^{[8-10]}$ Candidate genes are further evidence for a genetic predisposition. ${ }^{[8,10]}$

\section{Allergic sensitisation}

The predisposition for IgE hyper-responsiveness to allergens defines the term atopy. ${ }^{[1]} \mathrm{A}$ systematic review of the published evidence for allergic sensitisation and dermatitis in 12 population studies worldwide has shown that IgE hyper-responsiveness does not necessarily equate to $\mathrm{AD}$, even though it may be associated with the disease phenotype, especially in severe disease ${ }^{[2,11]}$ Geographical location was associated with the risk of being atopic among those with AD compared with normal healthy controls.

In five studies that included adolescents and adults, the findings were essentially similar. In a cross-sectional household survey from Ethiopia, which included adults and children, $15 \%$ of those with AD and $8 \%$ of those without $\mathrm{AD}$ were atopic on skin-prick testing. ${ }^{[12]}$ This lack of association between $\mathrm{AD}$ and allergen sensitisation in that setting was confirmed in a cross-sectional survey and nested casecontrolled study in children.

\section{Environment}

An increasing prevalence of $\mathrm{AD}$ over the past 50 years is not consistent with genetic drift alone, but supports a strong environmental influence as evidenced by population migration studies. ${ }^{[13]}$ These environmental influences, which affect initial disease expression or aggravation of established disease, are summarised below. However, population studies from Africa seldom confirm a role for the environmental factors. ${ }^{[12]}$ Interestingly, many are surrogate markers of urbanisation $^{[14]}$ and increased socioeconomic status, ${ }^{[14]}$ which appear to be the only fairly consistent associations across all population groups.

The aetiopathogenesis of $\mathrm{AD}$ is best explained by the concept of a damaged barrier function, whether intrinsically normal or dysfunctional, that induces a state of epidermal repair, coupled with aberrant responses to epidermal insults of the affected skin. ${ }^{[8,10,14,15]}$ In Africa, this hypothesis has not yet been validated. A novel filaggrin gene defect has been documented in a single Ethiopian case of $\mathrm{AD}{ }^{[16]}$ What evolutionary advantage the skin barrier defect conveyed to the populations now exposed to environmental influences precipitating atopic disease, is unknown. 


\section{Environmental influences}

The following factors have been shown to increase the risk for/ prevalence of $\mathrm{AD}$ :

- rural compared with urban living (hygiene hypothesis) ${ }^{[13,14,17,18]}$

- maternal AD history (parent-of-origin effect) ${ }^{[10,18,19]}$

- higher socioeconomic status ${ }^{[12,14,20]}$

- higher educational level of parents ${ }^{[21]}$

- smaller family size (hygiene hypothesis) ${ }^{[17,22]}$

- improved basic hygiene (hygiene hypothesis) ${ }^{[17]}$

- antibiotic use early in life (hygiene hypothesis) ${ }^{[17,21]}$

- caesarean section delivery ${ }^{[23]}$

- increased maternal age ${ }^{[19]}$

- environmental tobacco smoke (major risk) ${ }^{[13]}$

- contact dermatitis ${ }^{[24,25]}$

- cooler climates ${ }^{[3]}$

- clothing with rough fibres ${ }^{[26]}$

- environmental pollution ${ }^{[13,17]}$

- psychosocial stress. ${ }^{[21,23]}$

The following factors have been shown to decrease the risk for/ prevalence of $\mathrm{AD}$ :

- day-care attendance ${ }^{[17]}$

- animal exposure early in life (hygiene hypothesis) $)^{[17,21,23]}$

- endotoxin exposure in early infancy (hygiene hypothesis) ${ }^{[17]}$

- infections early in life (hygiene hypothesis) ${ }^{[17]}$

- breastfeeding ${ }^{[19,27,28]}$

- fully hydrolysed formula feeds ${ }^{[21,27,28]}$

- vaccination (hygiene hypothesis). ${ }^{[17,19]}$

The following factors have not been inconclusively shown to affect the risk for/prevalence of $\mathrm{AD}$ :

- parasite infestation ${ }^{[15,17]}$

- maternal diet ${ }^{[18,19,23,26,28]}$

- maternal probiotic use ${ }^{[19,23,26]}$

- diet restriction ${ }^{[21,27]}$

- elemental $\operatorname{diet}^{[21,27]}$

- organic food ${ }^{[21]}$

- solid food introduction ${ }^{[21,27]}$

- diet supplementation with antioxidants, essential fatty acids, probiotics ${ }^{[18,19,21,26-28]}$

- staphylococcal control ${ }^{[18,21,26]}$

- hard water - no effect if calcium carbonate is removed ${ }^{[20}$

- reduced house dust mite exposure ${ }^{[18,21,26]}$

- clothes softeners. ${ }^{[26]}$

\section{Food allergy}

The inter-relationship between $\mathrm{AD}$ and food allergy is complex. Many patients and/or their carers believe that it is caused by something in their diet; however, it is rarely diet alone that triggers AD. Tests for food allergy should not routinely be done in all cases of AD. Concomitant or causative food allergy should be considered in patients with a convincing history of food allergy and those with moderate to severe eczema that does not respond to appropriate and adequate topical treatment.

Sensitisation to foods (raised ImmunoCAP values or positive skin-prick tests) is common in $\mathrm{AD}$, but not synonymous with clinically relevant food allergy. About $60 \%$ of patients with $\mathrm{AD}$ are sensitised to food allergens ${ }^{[29]}$ - a much higher percentage than the overall prevalence of food sensitisation in the general population. In 2011, infants attending a tertiary dermatology clinic for $\mathrm{AD}$ were shown to have high sensitisation rates $(66 \%$ to at least one food), most commonly to egg (52\%), peanuts (39\%) and cow's milk $(25 \%) \cdot{ }^{[30]}$

Approximately $30-40 \%$ of children with $\mathrm{AD}$ have a co-existing food allergy, ${ }^{[29]}$ but this is much less common in adults.

\section{References}

Johansson SGO, Bieber T, Dahl R, et al. Revised nomenclature for allergy for global use: Report of the Nomenclature Review Committee of the World Allergy Organization, October 2003. J Allergy Clin Immunol 2004;113:832-836. [http://dx.doi.org/10.1016/j.jaci.2003.12.591]

2. Flohr C, Johansson SGO, Wahlgren C-F, Williams H. How atopic is atopic dermatitis? J Allergy Clin Immunol 2004;114:150-158. [http://dx.doi.org/10.1016/j.jaci.2004.04.027]

3. Tokura Y. Extrinsic and intrinsic types of atopic dermatitis. J Dermatol Sci 2010;58:1-7. [http://dx.doi. org/10.1016/j.jdermsci.2010.02.008]

4. Simpson EL, Hanifin JM. Atopic dermatitis. Med Clin N Am 2006;90:149-167. [http://dx.doi org/10.1016/j.mcna.2005.09.002]

. Wolf R, Wolf D. Abnormal epidermal barrier in the pathogenesis of atopic dermatitis. Clin Dermatol 2012;30:329-334. [http://dx.doi.org/10.1016/j.clindermatol.2011.08.023]

6. Irvine AD, Irwin McLean WH, Leung DYM. Filaggrin mutations associated with skin and allergic disease. N Engl J Med 2011;365:1315-1327. [http://dx.doi.org/10.1056/NEJMra1011040]

7. Sandström Falk MH, Faergemann J. Atopic dermatitis in adults: Does it disappear with age? Acta Derm Venereol 2006;86:135-139.

8. Schultz Larsen F. Genetic epidemiology of atopic dermatitis. In: Williams HC. Atopic Dermatitis. The Epidemiology, Causes and Prevention of Atopic Dermatitis. Cambridge: Cambridge University Press, 2000:113-124. [http://dx.doi.org/10.1017/CBO9780511545771.010]

9. Schultz Larsen F. Atopic dermatitis: A genetic-epidemiologic study in a population-based twin sample. J Am Acad Dermatol 1993;28:719-723. [http://dx.doi.org/10.1016/01909622(93)70099-F]

10. Morar N, Willis-Owen SAG, Moffatt MF, Cookson WOCM. The genetics of atopic dermatitis. J Allergy Clin Immunol 2006;118:24-34. [http://dx.doi.org/10.1016/j.jaci.2006.03.037]

11. Williams $\mathrm{H}$, Flohr $\mathrm{C}$. How epidemiology has challenged 3 prevailing concepts about atopic dermatitis. J Allergy Clin Immunol 2006;118:209-213. [http://dx.doi.org/10.1016/j. jaci.2006.04.043]

12. Yemaneberhan H, Flohr C, Bekele Z, et al. Prevalence and associated risk factors of atopic dermatitis symptoms in rural and urban Ethiopia. Clin Exp Allergy 2004;34:779-785. [http://dx.doi.org/10.1111/ j.1365-2222.2004.1946.x]

13. Burrell-Morris C, Williams HC. Atopic dermatitis in migrant population. In: Williams HC. Atopic Dermatitis. The Epidemiology, Causes and Prevention of Atopic Dermatitis. Cambridge: Cambridge University Press, 2000:169-182. [http://dx.doi.org/10.1017/ CBO9780511545771.015

14. Obeng BB, Hartgers F, Boakye D, Yazdanbakhsh M. Out of Africa: What can be learned from the studies of allergic disorders in Africa and Africans? Curr Opin Allergy Clin Immunol 2008;8:391-397. [http://dx.doi.org/10.1097/ACI.0b013e32830ebb70]

15. Roduit $\mathrm{C}$, Wohlgensinger I, Frei R, et al. Prenatal animal contact and gene expression of innate immunity receptors at birth are associated with atopic dermatitis. J Allergy Clin Immunol 2011;127:179-185. [http:// dx.doi.org/10.1016/j.jaci.2010.10.010

16. Winge MCG, Bilcha KD, Lieden A, et al. Novel filaggrin mutation but no loss-of-function variants found in Ethiopian patients with atopic dermatitis. Br J Dermatol 2011;165:1074-1080. [http://dx.doi org/10.1111/j.1365-2133.2011.10475.x]

17. Flohr C, Pascoe D, Williams HC. Atopic dermatitis and the 'hygiene hypothesis': Too clean to be true? Br J Dermatol 2005;152:202-216. [http://dx.doi.org/10.1111/j.13652133.2004.06436.x] 
18. Shams K, Grindlay DJC, Williams HC. What's new in atopic dermatitis? An analysis of systematic reviews published in 2009-2010. Clin Exp Dermatol 2011:36:573-578. [http://dx.doi. org/10.1111/j.1365-2230.2011.04078.x]

9. Godfrey K. Fetal and perinatal origins of atopic dermatitis. In: Williams HC. Atopic Dermatitis. The Epidemiology, Causes and Prevention of Atopic Dermatitis. Cambridge: Cambridg University Press, 2000:125-138. [http://dx.doi.org/10.1017/CBO9780511545771.01]

20. McNally N, Phillips D. Geographical studies of atopic dermatitis. In: Williams HC. Atopic Dermatitis. The Epidemiology, Causes and Prevention of Atopic Dermatitis. Cambridge: Cambridge University

Press, 2000:71-84. [http://dx.doi.org/10.1017/CBO9780511545771.012]
21. National Institute for Health and Clinical Excellence. Atopic dermatitis in children. Management of atopic dermatitis in children from birth up to the age of 12 years. NICE Clinical Guideline 57. London: NICE, 2007

2. McNally N, Phillips D. Social factors and atopic dermatitis. In: Williams HC. Atopic Dermatitis. The Epidemiology, Causes and Prevention of Atopic Dermatitis. Cambridge: Cambridg University Press, 2000:139-154. [http://dx.doi.org/10.1017/CBO9780511545771.012]

23. Williams HC, Grindlay DJC. What's new in atopic dermatitis? An analysis of systematic reviews published in 2007 and 2008. Part 1. Definitions, causes and consequences of dermatitis. Clin Exp Dermatol 2009;35:12-15. [http://dx.doi.org/10.1111/j.1365-2230.2009.03733.x]
24. Bonitas NG, Tatsioni A, Bassioukas K, Ioannidis PA. Allergens responsible for allergic contac dermatitis amongst children: A systematic review and meta andysis. Conter Dermatitis 2011:64:245257. [http://dx.doi.org/10.1111/j.1600-0536.2010.01860.x]

25. Czarnobilska E, Obtulowicz K. Dyga W, Spiewak R. A half of schoolchildren with ISAAC dermatitis are ill with allergic contact dermatitis. J Eur Acad Dermatol Venereol 2011;25:1104-1107. [http:// dx.doi.org/10.1111/j.1468-3083.2010.03885.x]

26. Hoare C, Li Wan Po A, Williams H. Systematic review of treatments for atopic dermatitis. Healt Technology Assessment 2000;4(37):1-19

27. Batchelor JM, Grindlay DJC, Williams HC. What's new in atopic dermatitis? An analysis of systematic reviews published in 2008 and 2009. Clin Exp Dermatol 2010;35:823-828. [http://dx.doi.org/10.1111/j.13652230.2010.03901.x]

28. Muche-Borowski C, Koop M, Reese I, et al. Allergy prevention. Dtsch Arztebl Int 2009;106:625-631. [http://dx.doi.org/10.3238/arztebl.2009.0625]

9. Suh K-Y. Food allergy and atopic dermatitis: Separating fact from fiction. Semin Cutan Med Sur 2010;29:72-78. [http://dx.doi.org/10.1016/j.sder.2010.03.007]

30. Gray C. A prospective descriptive study to determine the prevalence of IgE-mediated food allergy in South African children with atopic dermatitis attending a tertiary medical centre: Review of the first 80 patients Abstract. South African Journal of Child Health 2011;5(3):99.

\section{ABSTRACT}

\section{Is BCG vaccination effective against Mycobacterium tuberculosis in children?}

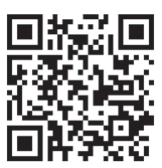

We know from numerous efficacy trials over several decades that bacillus Calmette-Guérin (BCG) has $60-80 \%$ protective efficacy against severe forms of tuberculosis (TB) in children, particularly meningitis, but that its efficacy against pulmonary disease varies geographically. The latter is probably because BCG does not seem to protect against disease when given to those already infected or sensitised to environmental mycobacteria. The purpose of this recent study was to determine whether BCG vaccination protects against Mycobacterium tuberculosis infection, as assessed by interferon $\gamma$ release assays (IGRA) in children.

Roy et al. conducted a systematic review and meta-analysis using searches of electronic databases from 1950 to November
2013. Inclusion criteria were vaccinated and unvaccinated children under 16 years of age with known recent exposure to patients with pulmonary TB. Children were screened for $M$. tuberculosis infection with IGRA. Primary analysis included 14 studies and 3855 participants. The estimated overall risk ratio was 0.81 , indicating a protective efficacy of $19 \%$ against infection among vaccinated children after exposure compared with unvaccinated children. Among those infected, protection against progression to disease was $58 \%$. This study suggests that BCG protects against $M$. tuberculosis infection and progression from infection to disease.

Roy A, Eisenhut M, Harris RJ, et al. Br Med J 2014;349:g4643. [http://dx.doi.org/10.1136/bmj.4643]

The full version of the article is available online. Use the QR code above to access. 